\title{
Portas de entrada ou portas fechadas? $O$ acesso à reabilitação nas Unidades Básicas de Saúde da região sudeste do município de São Paulo - período de 2000 a 2006*
}

\section{Entry doors or shut doors? Access to rehabilitation within basic health units of the southeastern region of the city of So Paulo - from 2000 to 2006}

\author{
Camila Cristina Bortolozzo Ximenes de Souza ${ }^{1}$, \\ Eucenir Fredini Rocha ${ }^{2}$
}

SOUZA, C. C. B. X.; ROCHA, E. F. Portas de entrada ou portas fechadas? O acesso à reabilitação nas unidades básicas de saúde da região sudeste do município de São Paulo - período de 2000 a 2006. Rev. Ter. Ocup. Univ. São Paulo, v. 21, n. 3, p. 230-239, set./dez. 2010.

\begin{abstract}
RESUMO: Desde a Constituição Federal de 1988, o acesso equânime e universal a saúde é direito de todo cidadão brasileiro. Entretanto, tal direito encontra inúmeras barreiras para a sua efetivação, uma vez que nem todos os usuários do SUS têm acesso aos serviços de saúde, a exemplo das pessoas com deficiência e/ou incapacidades. Este artigo discute os resultados de pesquisa realizada junto ao PSF - QUALIS/Fundação Zerbini, e objetivou conhecer as vivências de usuários com deficiências e familiares ao utilizarem o serviço de reabilitação deste programa, e compreender como avaliam o acesso que têm ao mesmo, levando em conta diferentes discursos, posições sociais, e origens culturais, por meio de entrevistas semi-estruturadas e emprego de metodologia qualitativa. Foi possível perceber que a equipe de reabilitação comprometia-se com a qualidade de vida da população, realizando acompanhamento longitudinal das famílias; facilitando o acesso através de busca ativa e atendimento domiciliar. Entretanto, diversas barreiras ao acesso, principalmente arquitetônicas, foram mencionadas pelos entrevistados. Com a pesquisa foi possível detectar que mesmo com as estratégias utilizadas pela equipe de reabilitação, o tema acesso necessita ser mais discutido e pensado de forma sistêmica por usuários, profissional de saúde, serviços, políticas públicas e órgãos governamentais para que seja construído de forma efetiva e universal.
\end{abstract}

DESCRITORES: Serviços de saúde/utilização; Pessoa com deficiência/reabilitação; Saúde da Família. Serviços de reabilitação. Centros de saúde; Atenção primária a saúde.

\footnotetext{
* Artigo realizado a partir dos resultados de monografia intitulada: "O PSF vivido e o pensado - Leitura dos usuários com deficiência e familiares sobre o acesso ao serviço de reabilitação no PSF/QUALIS-Fundação Zerbini - Região Sudeste de São Paulo". Apresentado no X Congresso Brasileiro de Terapia Ocupacional, 2007.

1. Mestranda do Departamento de Medicina Preventiva da Faculdade de Medicina da Universidade de São Paulo, e Terapeuta Ocupacional do Departamento de Fisioterapia, Fonoaudiologia e Terapia Ocupacional da Faculdade de Medicina da Universidade de São Paulo. Email: camila.reata@usp.br

2. Prof $^{a} \operatorname{Dr}^{\mathrm{a}}$, docente do Departamento de Fisioterapia, Fonoaudiologia e Terapia Ocupacional da Faculdade de Medicina da Universidade de São Paulo. E-mail: eucenir@usp.br

Endereço para correspondência: Rua Cipotânea, 51 - Cidade Universitária. CEP. 05360-160 - São Paulo - SP.
} 


\section{APRESENTAÇÃO}

$\mathrm{C}$ om a Constituição de 1988, e a legislação subseqüente ${ }^{1}$ está garantido o direito universal e integral à saúde para todos. Dessa forma está assegurada a atenção à saúde e reabilitação de pessoas com deficiência e/ou incapacidades no Sistema Único de Saúde (SUS).

Em 1993, o Ministério da Saúde (MS) lançou o documento "Atenção à Pessoa Portadora de Deficiência no SUS: Planejamento e Organização de Serviços" (BRASIL, 1993) com orientações aos gestores municipais e estaduais para a implantação de ações de reabilitação descentralizadas, em todos os níveis de atenção, com organização de referências e contra-referências, em consonância com as recomendações das Organizações Pan-Americana de Saúde (OPAS) e Mundial de Saúde (OMS)

Entretanto, nos anos subseqüentes (1990-2000), a assistência à saúde da pessoa com deficiência ainda apresentou dificuldades de se constituir de forma orgânica. A tradição de oferta de serviços especializados em grandes centros urbanos prevaleceu, com a inserção desses serviços no nível secundário ou terciário (ROCHA, 2006). Assim, mesmo com o processo de regionalização e descentralização dos serviços, muitos usuários com deficiência têm encontrado dificuldades de usufruírem de todos os recursos do SUS, pois, ainda são restritas as ofertas de ações de reabilitação em todos os níveis assistenciais.

Mesmo quando essa modalidade assistencial é ofertada na Unidade Básica de Saúde (UBS), na Atenção Primária a Saúde (APS), muitas pessoas com deficiência não conseguem sair de seus domicílios devido às dificuldades de locomoção, transporte, ausência de acompanhantes, gravidade da patologia, ausência de equipamentos de ajuda (cadeira de rodas, próteses, órteses, bengalas, andadores e muletas), barreiras arquitetônicas no domicílio ou arredores e espaços públicos (SOUZA, 2006).

Com a recente implantação dos Núcleos de Apoio à Saúde da Família (NASF) (BRASIL, 2008) em diferentes regiões do país, as questões de saúde e reabilitação da pessoa com deficiência ou incapacidade estão entrando na pauta das ações da APS, porém ainda são consideradas por diversos gestores e profissionais (ROCHA; KRETZER, 2009), como de responsabilidade do nível secundário e terciário.
Essa cultura que ainda prevalece na área da saúde determina, em muitas ocasiões, que esses usuários, mesmo quando chegam até as UBS, sejam encaminhados para serviços especializados. No entanto, muitos não conseguem chegar até os mesmos, ou porque não tem transporte e o equipamento de saúde fica distante da sua moradia, ou o deslocamento é oneroso, as filas de espera para inserção na agenda institucional são longas, ou ainda enfrentam situações de rejeição institucional por não se enquadrarem nos critérios de assistência das mesmas (ROCHA, 2006; SOUZA, 2006).

Dessa forma, a efetivação do direito universal à saúde, através da operacionalização de ações reabilitacionais em todos os níveis assistenciais, ainda necessita de muitos investimentos, tanto do ponto de vista organizacional, como de propostas técnicas adequadas às necessidades dessa população e de recursos humanos capacitados, de forma a garantir o acesso pleno aos serviços de saúde, nos diferentes níveis de atenção.

\section{Pessoa com Deficiência, Acesso, Integralidade e Atenção Primária}

Para Hortale et al. (2000) o acesso deve ser considerado como uma categoria valor, norteando todas as políticas públicas, devendo ser referência a ser perseguida pelos serviços.

Conill (2004) ressalta que a avaliação de medidas de acesso aos serviços de saúde está diretamente relacionada à questão da integralidade. Não se trata de afirmar que integralidade e acesso sejam sinônimos. Segundo a autora,

... não interessa ter acesso a cuidados parcelares e descontínuos. Ou seja, na realidade, o que vale a pena verificar é se está ocorrendo acesso a um sistema com cuidados integrais. A verificação das dimensões físicas do acesso, ou seja, da existência de recursos capazes de responder à demanda, dá também uma idéia das condições estruturais para que a integralidade possa ocorrer (p. 1420).

No Brasil, o conceito de integralidade está presente desde os anos 1980, inicialmente aplicado a programas abrangentes para grupos específicos ${ }^{2}(\mathrm{CONILL}, 2004)$,

1. Ver: 1. Lei no. $7.853 / 89$ que assegura o apoio a pessoa portadora de deficiência e a sua integração social. Dispõe ainda sobre a promoção de ações preventivas de saúde; 2. Decreto no. 3.298/99 que regulamenta a Lei no. 7.853 e dispõe sobre a Política Nacional para a Integração da Pessoa Portadora de Deficiência; e 3. Decreto no.914/93 que institui a Política Nacional para a Integração da Pessoa Portadora de Deficiência. 
sendo que em 1988 foi assumida como diretriz para a organização do SUS no texto constitucional. Pinheiro et al. (2003, p. 235) afirmam que a integralidade é um conjunto articulado de ações e serviços de saúde, preventivos e curativos, individuais e coletivos nos diversos niveis de complexidade do sistema.

Dessa forma, a caracterização desse princípio envolve a apreensão ampliada das necessidades da população, bem como a capacidade de adequar as intervenções em saúde ao contexto específico das realidades locais (MATTOS, 2004), reconhecer que as ações promocionais, preventivas e curativas devem ocorrer de forma simultânea e com a mesma importância, no mesmo espaço institucional dos serviços de saúde.

Aqui se parte da premissa que inexiste a possibilidade de construção da integralidade e da eqüidade sem que haja garantia de acesso universal a todos os níveis de atenção (PINHEIRO et al., 2003), o que implica o reconhecimento de ações recíprocas entre a macro e a micropolítica de saúde. Mas há de se destacar que o acesso ao serviço per si não garante ações integrais.

Atenção Básica (AB), denominação utilizada no Brasil desde a implantação do SUS para a APS (BRASIL, 2006), é avaliada no contexto internacional como o fundamento para um modelo assistencial em sistemas de saúde eficaz, que foca o usuário-cidadão, utilizando-se de um conjunto de práticas, desenvolvidas junto aos indivíduos e a coletivos (GIOVANELLA; MENDONÇA, 2008).

No bojo da reorganização da $\mathrm{AB}$, o princípio da eqüidade e integralidade aqueceu o debate sobre as formas de programar ações de saúde. Nesse cenário emergiu o Programa de Saúde da Família (PSF) ${ }^{3}$ como um modelo assistencial que diverge do modelo bio-médico e hospitalocêntrico, paradigma até então vigente (MERHY; FRANCO, 2003).

Dentro do paradigma do PSF, segundo Levcovitz e Garrido (1996),

...o que se busca é a integralidade da assistência, respondendo à demanda espontânea de forma contínua e racionalizada. ...no PSF se pretende tratar o indivíduo como sujeito, integrado no seu entorno, a partir de ações que valorizem essa dimensão mais globalizante. (1996, p.5)

Dessa forma, o PSF propõe não apenas a regionalização e a reorganização das práticas assistenciais, como também a redefinição do objeto de atenção das ações em saúde, que passa a ser entendido como a família, e não mais o indivíduo; e, prioritariamente, a adoção de práticas de cuidado, modificando a atuação profissional e a compreensão dos processos saúde-doença influenciados também pelas condições territoriais, sociais, biológicas e psicológicas (BRASIL, 2006).

Isto posto, é possível observar que as mudanças propostas pelo paradigma do PSF tendem a ser favoráveis ao trabalho vivo, no qual formas de abordagens mais relacionais são priorizadas, ...operando dentro da idéia de que no encontro entre trabalhador e usuário, este é também sujeito da produção da saúde e pode, desta forma, ser também protagonista de atos cuidadores, geradores de autonomia (MERHY; FRANCO, 2003, p.319). De acordo com esses autores, essa nova proposta, avessa ao modelo bio-médico, constitui a reestruturação produtiva e transição tecnológica da saúde (MERHY; FRANCO, 2003).

Levcovitz e Garrido (1996) colocam que a importância estratégica do PSF está no fato dele conseguir substituir a porta de entrada do sistema, propondo a efetivação da prevenção e promoção à saúde, a partir de três eixos:

1. Redefinição do objeto de atenção: do indivíduo e sua patologia para a família, entendida a partir do ambiente onde vive, comunidade e cultura onde se insere;

2. Alteração da forma de atuação: do consultório para a comunidade/família/território, utilizando-se de tecnologias, habilidades e competências específicas;

3. Reorganização da prática assistencial: estabelecimento de estratégias não verticais de intervenção, compreensão ampliada do processo saúde/doença, com intervenções de impacto e significado social, equipes com atuação inter e multidisciplinar, com responsabilidade integral sobre a população da área de abrangência.

A proposta ministerial não previa no lançamento do PSF ações de reabilitação e saúde mental, entre outras, o que limita as possibilidades de acesso, eqüidade e integralidade da pessoa com deficiência e/ou incapacidade.

A proposta do MS de criação do NASF (BRASIL,

2. Como foi o caso do Programa de Atenção Integral à saúde da mulher e o Programa de atenção integral à saúde da criança (CONILL, 2004).

3. Programa da Saúde da Família (PSF): atualmente denominado de Estratégia da Saúde da Família (ESF) ou apenas de Saúde da Família (SF). Nesse artigo utilizaremos PSF, tal como denominado na época do desenvolvimento da pesquisa. 
2008) objetiva a ampliação da resolutividade da APS (BRASIL, 2008).

As ações de reabilitação compõem um dos núcleos de ação dos NASF e entende-se esta política como um facilitador ao processo de territorialização desses serviços podendo facilitar o acesso das pessoas com deficiência aos mesmos (ROCHA; KRETZER, 2009).

Pretende-se aqui apresentar os resultados de pesquisa realizada junto às Unidades Básicas de Saúde com PSF da região sudeste do município de São Paulo, no período de 2005/06, que objetivou conhecer as vivências dos usuários com deficiências e familiares no que se refere ao acesso às ações/serviço de reabilitação do PSF/QUALIS-Fundação Zerbini.

\section{O território e os Serviços de Saúde Pesquisados}

A pesquisa foi realizada no município de São Paulo, Vila Prudente e Sapopemba, localizada no extremo sudeste da cidade (Figura1).

Figura 1 - Município de São Paulo. Destaque: Região de Vila Prudente/Sapopemba

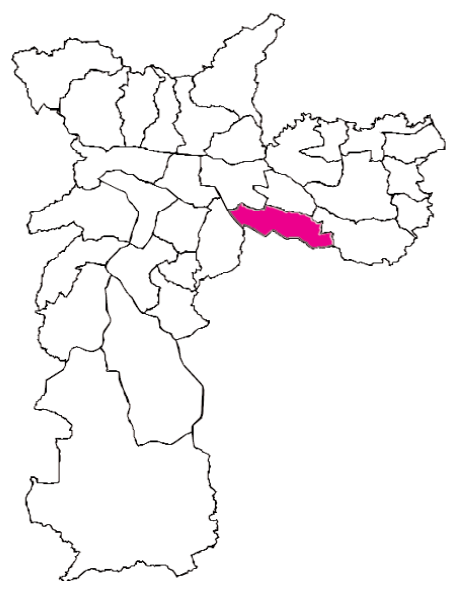

As UBS pesquisadas estiveram sob a administração da Fundação Zerbini em parceira com a Secretaria de Saúde do município de São Paulo, de fevereiro de 1998 até fevereiro de 2007. Compunham o trabalho, nove UBS (Figura 2), com 33 equipes de saúde da família, responsáveis por 42.000 famílias, perfazendo um total de 171.600 pessoas. Como infra-estrutura da proposta havia também equipes de saúde bucal para todas as equipes de saúde da família, um ambulatório de especialidades médicas, uma equipe de saúde mental, uma equipe de reabilitação e uma Casa de Parto (ROCHA e KRETZER, 2009). Todos esses recursos eram exclusivos para os usuários das nove UBS.

Figura 2 - Localização das UBS pesquisadas

\section{QUALI8-ZONA BUDE ITE}

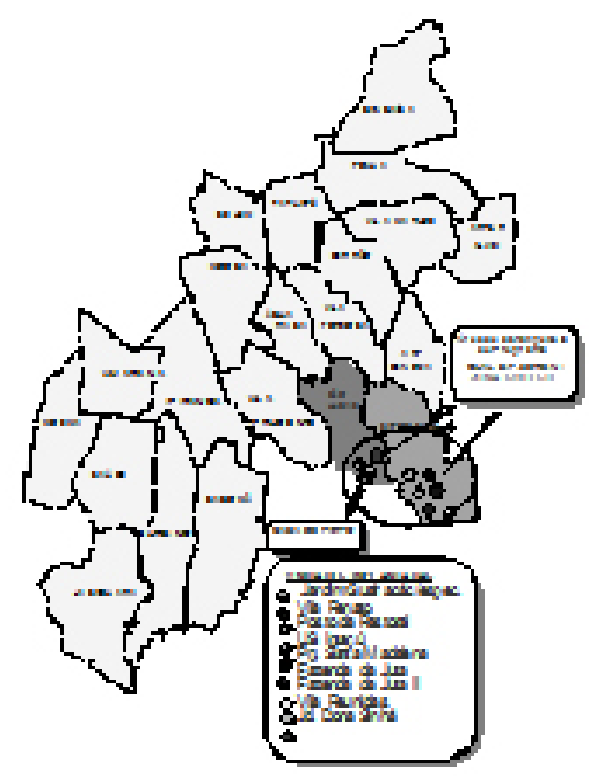

\section{PROCEDIMENTOS METODOLÓGICOS}

Este artigo é resultado do trabalho de conclusão de curso de graduação em Terapia Ocupacional (TO) da Universidade de São Paulo. O projeto foi submetido e aprovado pelo Comitê de Ética da Secretaria Municipal de Saúde ${ }^{4}$.

Trata-se de um estudo qualitativo, cuja finalidade foi entender o que usuários com deficiência e seus familiares pensam sobre o acesso aos serviços de reabilitação do PSF, levando em conta diferentes discursos, posições sociais e origens culturais.

Objetivou também compreender as possíveis

4. Comitê de Ética em Pesquisa da Coordenação de Desenvolvimento de Programas de Políticas de Saúde (CODEPPS) da Secretaria Municipal de Saúde do Município de São Paulo Projeto no: CAAE 0110/2006, Parecer nº: 202/2006/CEP/SMS. 
dificuldades da construção de um serviço que esteja efetivamente interessado na defesa da vida, centrado nas necessidades do usuário (MERHY; FRANCO, 2003).

\section{Coleta de dados}

Foram realizadas dezoito entrevistas, sendo nove com pessoas com deficiência, e nove com familiares de pessoas com deficiência. Os familiares entrevistados não eram da mesma família das pessoas com deficiência entrevistadas, buscando-se com isso, diversidade das problemáticas vivenciadas, diferentes localizações territoriais das residências e a abordagem de um maior número de famílias.

Optou-se por entrevistas semi-estruturadas com as seguintes perguntas: "como você descreve o acesso que você tem ao serviço de reabilitação da UBS?"; "qual o seu grau de satisfação com as ações deste serviço?"; "você tem alguma sugestão de mudança?"; "você gostaria de falar sobre algo que eu não perguntei?".

Os entrevistados foram incentivados a falar livremente sobre suas experiências de acesso e usufruto dos serviços, pois as questões abertas permitiram desmembramentos nos depoimentos, dentro do campo abordado.

O convite para a participação das entrevistas foi realizado em parceria com os Agentes Comunitários de Saúde (ACS), uma vez que eles possuíam um vínculo maior com a população do que o pesquisador, além de facilitarem a entrada na comunidade. Todas as entrevistas foram realizadas nas residências dos indivíduos selecionados, e todos os cuidados éticos foram tomados, incluindose a apresentação do Termo de Consentimento Livre e Esclarecido.

\section{Análise dos dados}

As entrevistas foram gravadas e transcritas. Foram analisadas na perspectiva de se detectar como esses usuários observaram e avaliaram as dimensões físicas, os recursos e condições estruturais oferecidos pelas UBS e equipes para se obter uma assistência integral e equânime em saúde. Analisou-se também a capacidade dos usuários em avaliar a oferta dos serviços do ponto de vista individual e coletivo, das ações preventivas e curativas.

Assim, a análise privilegiou os conteúdos manifestos, as significações explícitas dos discursos, ou seja, realizouse uma análise temática indutiva, tratada a luz de autores como Conill, Franco, Hortalle, Mattos, Merhy, Pinheiro e Rocha, que discutem reabilitação, acesso, integralidade e modalidades assistenciais em saúde coletiva, e suas relações com cidadania.

Foram realizadas leituras intensas das transcrições através das quais foi possível realizar agrupamentos temáticos dos conteúdos dos depoimentos. Em seguida, realizou-se análise dos temas evidenciados nos agrupamentos dos conteúdos na perspectiva da bibliografia estudada.

\section{RESULTADOS}

A equipe de reabilitação das UBS estudadas foi criada com a perspectiva de universalizar o acesso da população aos serviços públicos de saúde. No entanto, foi possível observar através dos depoimentos, que do ponto de vista dos usuários, muitos fatores ainda atravancam a universalização do acesso, não apenas aos serviços de reabilitação, como também aos serviços de saúde em geral.

Durante as entrevistas, os sujeitos da pesquisa abordaram dimensões semelhantes em relação às possibilidades de usufruírem dos serviços de saúde e reabilitação do PSF, tais como: implicações dos fatores ambientais e relacionais no acesso; satisfação em relação ao serviço e à qualidade; resolutividade das ações de reabilitação e necessidades de mudanças.

\section{Fatores ambientais e as possibilidades de acesso}

São considerados fatores ambientais os espaços de circulação, o mobiliário ${ }^{5}$ e todos os outros aspectos que condicionam a chegada ao equipamento de saúde, como os espaços do entorno, as calçadas, calçamentos das vias públicas e transporte.

Os entrevistados denunciaram os aspectos da acessibilidade arquitetônica e urbana, como fatores importantes na determinação da possibilidade de acessar os serviços de saúde, pois muitas pessoas com deficiência têm dificuldades de deslocamento nesses espaços.

Especificamente em relação às condições estruturais das UBS, muitas têm rampas íngremes, escadas, corredores estreitos, ausência de banheiros adaptados, entre outros problemas arquitetônicos, que dificultam a circulação de pessoas com mobilidade reduzida. O entorno das UBS

5. Considerou-se aqui a adequação do mobiliário como proposto pelo Conselho Regional de Engenharia Arquitetura e Agronomia de São Paulo (CREA-SP) que prevê a utilização do desenho universal na confecção. Desenho Universal. 
possuem degraus, buracos nos pisos, e presença de outras barreiras ao acesso:

\begin{abstract}
...aqui a rua é muito ruim... pra nós e pra quem tá ajudando a gente empurrar a cadeira $(U 1)^{6}$

Aqui em São Paulo tem um problema crônico: tem guia baixa, só que... vai reformando, e a rua é mais alta do que a calçada de tanta reforma que teve na rua. E os outros acham que essa guia baixa vai resolver o problema da acessibilidade.(U2)

...não tem elevador nem nada, as pessoas têm que levar a gente no braço... nas salas do posto não tem espaço pra mim entrar com a cadeira. (U3)

Porque você vai pegar um ônibus e não tem naquela linha ônibus pra deficiente... e quando tem você não sabe se pega, porque ou tá quebrado, ou tá lotado, cheio de gente no lugar que era pra ir a cadeira de rodas.(U4)

Não tem ônibus direto! E tem um negócio chamado Atende ${ }^{7}$ que eu acho que não atende nem o telefone!(U5)
\end{abstract}

\section{Os fatores relacionais na determinação do} acesso

As relações entre usuários, cuidadores e profissionais também condicionam o acesso ao serviço. Os depoimentos demonstram que a presença de reabilitação no PSF aproxima de forma significativa os profissionais dos usuários e comunidade.

Os entrevistados manifestaram em sua maioria estarem satisfeitos com as relações estabelecidas com a equipe de reabilitação, uma vez que o atendimento se tornou mais humanizado e com melhor qualidade, proporcionando a criação de vínculos importantes para os processos terapêuticos, com respostas adequadas às necessidades:

Eu num tive dificuldade pra começa o tratamento porque quando eu adoeci... sem locomoção, essa coisa do pessoal do posto vir em casa já ajudou muito... a Agente(ACS) já viu que eu fiquei doente, veio aqui em casa, já fez a minha ficha, ejá veio tudo. Eles vêm sempre aqui pra saber como que eu tô, pra fazer o tratamento, e eu acho isso muito importante.(U6)

No entanto, também existem muitas dificuldades relacionadas ao fato da instituição não atender todas as necessidades desses usuários, porque os profissionais não se consideram responsáveis ou habilitados para assistir essa população:

\begin{abstract}
Mas no posto ela não teve atendimento. Lá não entro mais nunca! A gente chega lá e elas diz: 'ah, pra esse problema dessa menina a gente aqui não tem equipamento...' Mas será que eles não pode bota um termômetro ou escuta o peitinho da menina?(F1)
\end{abstract}

E às vezes nem é coisa pra reabilitação, às vezes é só uma gripe. E eles ficam jogando a gente pra outros lugares. $(F 2)$

Outro fator relacional que interfere no acesso é a existência ou não de um cuidador que possa acompanhar a pessoa com deficiência nos atendimentos de saúde. Esse fator não está relacionado diretamente com os profissionais das UBS, no entanto, modalidades alternativas de assistência, como atendimento domiciliar pode resolver em parte esse problema:

Eu preciso de duas pessoas pra me colocar na cadeira de rodas.(U3)

Se eu tenho alguma coisa pra ir fazer no posto, eu tenho que arrancar um dos meus filhos do serviço pra podê me levá. E... eles trabalham.(U6)

...eu tô doente dessa perna e não consigo mais levá ela pra fazê fisioterapia.(F5)

Assim, o fato de haver um serviço domiciliar de reabilitação é considerado pela maioria dos entrevistados como um facilitador, pois não restringe o direito à assistência àqueles que se deslocam de forma independente. Vale ressaltar que quando o usuário necessita de outros serviços de saúde nas UBS ou em serviços de nível secundário ou terciário, a questão da restrição ao acesso permanece:

A dificuldade é grande quando tem que ir fazer o tratamento no posto, por que a gente não tem como ir.. se eles dão a assistência de vir até aqui...É isso que nós necessitava." (U7)

"No posto, eles já vêm até aqui em casa, acompanha o serviço que tá sendo feito. Eu não tenho que enfrentar as dificuldades de sai de casa pra poder ir me tratar. (U3)

Para eliminar as barreiras de acesso vinculadas à fatores relacionais, também são necessárias políticas publicas que democratizem o acesso aos equipamentos

6. Os entrevistados foram identificados da seguinte forma: usuários (U) e Familiares (F).

7. ATENDE é o Serviço de Atendimento Especial, criado pelo decreto 36.071, de 9/5/1996. É definido pela prefeitura de São Paulo como transporte municipal gratuito, porta-a-porta, para pessoas com deficiência ou incapacidades e dependentes que não consigam utilizar outro meio de transporte público. 
de ajuda, como cadeiras de rodas novas e eficientes, mais transporte urbano adaptado e que possibilitem a existência de cuidadores sociais, de acordo com as necessidades de cada usuário/território.

\section{Satisfação dos usuários com os serviços}

Aqui parte-se do pressuposto que os usuários são os melhores avaliadores dos serviços que usufruem. Entender o usuário como capaz de avaliar o serviço de saúde que utiliza é também entendê-lo como possuidor de outro papel que não o de usuário, é entendê-lo como cidadão e financiador do serviço público. É quebrar as monoidentidades criadas pela reificação do indivíduo à patologia, nas quais o sujeito com deficiência fica restrito a um único papel social: o de deficiente - e aí não se fala em "pessoa com deficiência", porque a palavra "pessoa" não caberia a esta monoidentidade, uma vez que tende a atribuir características complexificantes, sendo contrária à redução do indivíduo (AMIRALIAN et al., 2000).

Os entrevistados não se furtaram a possibilidade de uma avaliação mais abrangente do serviço oferecido. Aspectos positivos, negativos foram apresentados ora isoladamente, ora juntos, demonstrando que essas pessoas se sentiram livres em suas opiniões

A humanização da atenção e das relações com a equipe de saúde da família e de reabilitação; o vínculo que estabeleceram com os terapeutas que permitiu aos usuários identificar tais profissionais como suporte ou referência para problemas de quaisquer ordens, seus ou familiares; os atendimentos domiciliares e a competência técnica dos profissionais foram os aspectos positivos elencados:

Tô satisfeita... a fisio, a TO, o fono, até agora eu não tive problema nenhum! Porque nos centros de reabilitação por ai, você pode ficar um certo tempo. Se deu pra resolver os teus problemas bem, se não deu você tem que sair e tchau. Aqui não, eles acompanham o meu filho, não tem previsão pra terminar, com falta você não perde a vaga e nem nada... Eu sei que se um dia eu precisar faltar por algum problema, eu sei que a vaga do meu filho tá aí. (F3)

"Mas eu acho que também vai de confiança. Porque se alguém fica doente aqui em casa eu não vou procurar o $I V A^{8}$, eu vou procurar o posto. (F4)

eu acho que a L [fisioterapeuta] me atendia como uma pessoa, um ser de carne e osso, um ser na integra, e não uma doença.(U3) ...o tratamento também consegue ajudar n'alguma tristeza, tenho tanto o tratamento físico como o mental. Ajuda muito... e ela [TO] vai dando aquele sentido pra vida, $e$ o incentivo pra gente ir se acalmando mais e continuar! (U5)

E uma coisa que eu acho bom, é que nos atendimento que o meu marido recebe, eu não fico de escanteio não. Eu também tô me tratando. Porque eu também tô até sendo terapeuta! [risos] Porque ela ensinou assim uns exercícios prafazer nele.(F6)

Como fatores negativos relatam a dificuldade de se desvincular de profissionais que tiveram de deixar o PSF; a falta de profissionais para atender toda a demanda; o número reduzido de atendimentos recebidos da equipe; a falta de continuidade dos atendimentos; a insuficiência de devolutivas da parte das equipes de saúde da família e de reabilitação; o que faz com que muitos entrevistados relatem a sensação de terem sido esquecidos pelos profissionais reabilitadores:

\begin{abstract}
... a gente se apega tanto a esse povo, que quando elas saem, a gente fica chorando.(F7)

Primeiro veio aqui a ACS vê ele, depois de um tempo veio a $C$ [TO]. Ela fez tratamento nele um tempo, só que depois ela parou porque o caso dele também não vai mais evoluir. Mas eu acho que não deveria ser assim. Só porque a pessoa não parece que vai evoluir acaba o tratamento dela? Eu tô vendo ele piorar cada dia.(F8)
\end{abstract}

Só pra pegar a vaga que eu demorei bastante.(U2)

Eu tive que esperar 16 meses.(U5)

Com relação à resolutividade, nota-se que as maiores queixas dirigem-se às condições das UBS. Relatam problemas em relação à formação dos profissionais, ou dificuldades no atendimento médico e nos encaminhamentos para outros serviços, pois o sistema de referência e contrareferência não funciona. Especificamente em relação às ações de reabilitação, nota-se que o descontentamento maior está em torno da falta de profissionais, que gera pouca freqüência nos atendimentos, reduzidas vagas, e pouco tempo de consulta:

Pra passar ele no médico mesmo eu já peguei filas enormes com ele no colo, e não sou só eu, várias mães lá na fila com criança no colo, é uma fila única, tanto pra jovem quanto pra senhor de idade, criança no colo, cadeira de rodas. (F3)

8. A entrevistada faz referência a um hospital público da região de Sapopemba. 
O pessoal da reabilitação, eles são muito bacana... Só que vem uma vez, vem outra e... parece que esquece daquele paciente. Eu não tô falando que é culpa deles, porque a gente não sabe nem como que é as condições de trabalho deles, como eles trabalha, quantos tem que atender e tal... só que é isso que eu sinto, por mais que eu entenda...(F9)

\section{Quanto às sugestões de mudança}

Como já foram discutidas anteriormente, as sugestões de mudanças dirigem-se a soluções dos problemas acima apontados, como a presença de mais profissionais, mais atendimentos, serviços de referência e contra-referência, diminuição das barreiras arquitetônicas, entre outros. Além disso, a maioria dos entrevistados possui um serviço de reabilitação (e um sistema de saúde) idealizado, e que muitas vezes a imagem dos centros de reabilitação ou hospitais ricamente equipados são os mais presentes nos discursos enquanto desejáveis. Demonstram nessas falas o quanto a população, assim como muitos profissionais, ainda estão vinculados a um imaginário que preconiza a assistência em reabilitação como sendo altamente complexa, exigindo grande infra-estrutura:

Tem que ter esse trabalho do posto aqui dessa região, mas com mais profissional, mais espaço... e que atendessem um número considerável de pacientes... que corresponda às necessidades da região.(U5)

Eu montaria assim, tipo um hospital. Uma sala só de fisioterapia, com aquelas aparelhagem toda... Tá certo que esses aparelhos não adiantam muito se a gente não fizer a parte em casa, mas mesmo assim já ajuda bem. ... Mas no posto não tem, coitado! (U9)

Pagava um salário justo, pra eles não terem dois empregos e abandonarem a gente.(F3)

Existe uma norma, e as rampas não são feitas pra subir e descer cadeira de roda, mas pra subir carrinho de mercadoria do próprio posto. E... dentro do banheiro não é adaptado. Isso seria importante, interessante e necessário acontecer.(U3)

Os usuários enfatizam, ainda, a universalidade e eqüidade de acesso ao serviço como um ponto a ser melhorado:

...tem aquele que precisa mais, e tem aquele que precisa menos, mas não tem que atendê um e o outro não. Tem que atendê os dois!

Acho que se o serviço de saúde do governo tá aí, tem que atender todo mundo, qualquer hora, tem que tá com a porta aberta.(U3)

É interessante notar que a maioria dos entrevistados ao indicarem alterações no serviço não se inclui nessas propostas, nem afirmam possuir meios para gerar ou iniciar tais mudanças. Apesar do histórico de lutas sociais da região, poucos se referem ao controle social como um meio para chegar ao sistema de saúde sonhado, e nos discursos, essa busca por melhores condições de atendimento fica mais no campo da reclamação, exceto um entrevistado:

...eu penso que a gente precisa melhorar a participação da população com a participação nos conselhos gestores... porque se hoje o serviço é bom, foi graças a esse serviço em comum com os profissionais, com o poder público e com a população. Então a gente só tem a ganhar se a gente for aperfeiçoando o processo dos conselhos de saúde. (U3)

Ao ser questionado sobre os motivos que levam a população ao não-engajamento nos conselhos, responde:

As grandes mudanças só são feitas a partir de uma consciência politica por parte dos profissionais, e da população em geral.... porque se a população tivesse mais consciência politica, muitos problemas de saúde que têm não teria, pelo próprio serviço que o posto oferece, mas o número de participantes é muito reduzido... Se a população tivesse essa consciência, pra participar, não ia tratar a doença, ia tratar a saúde... mas se a população participar mais, e acreditar mais, vai perceber, vai descobrir que o Sistema Único de Saúde é o melhor plano de saúde que o cidadão brasileiro pode ter. E não é de graça não. É muito bem pago! (U3)

\section{CONSIDERAÇÕES FINAIS}

... no dia que não tiver nenhuma barreira de acesso à saúde, a gente pode dizer que o centro de saúde vai estar sempre aberto à população. (U3)

As ações de reabilitação no PSF são reconhecidas pelos entrevistados como um ganho na qualidade de vida. Os usuários demonstram vinculação com as propostas de reabilitação, apresentam adesão às orientações e reconhecem que a continuidade e integralidade da assistência geram benefícios. Se por um lado expressam contentamento com este serviço que os acolhe com integralidade e qualidade, por outro lado, também manifestam preocupação e medo de ficarem sem ele ou que a qualidade do mesmo fique comprometida. As ações preventivas e coletivas de reabilitação são minimamente 
citadas o que demonstra possuírem dificuldades de vislumbrar necessidades para além daquelas individuais, imediatas e curativas.

Vale ressaltar que os aspectos relacionados a fatores ambientais dos equipamentos de saúde são particularmente relevantes ao analisarmos as questões que facilitam ou dificultam o acesso da pessoa com deficiência e mobilidade reduzida aos serviços. Como lembrado por um dos entrevistados, embora exista legislação nacional que regulamenta e estabelece normas para a construção de edificações, mobiliário, e equipamentos urbanos acessíveis ${ }^{9}$, a construção desses espaços ainda não é efetiva no Brasil.

As condições de acessibilidade e adequação de mobiliário, narradas pelos entrevistados tanto com relação aos serviços de saúde, quanto em relação às casas dos usuários e território, eram bastante ruins, o que certamente influenciou a qualidade de vida dessas pessoas. A população em geral não se responsabiliza e não luta pela eliminação das barreiras arquitetônicas nos espaços públicos, e o Estado também se omite nessa tarefa, não providenciando as adequações necessárias nos equipamentos e espaços públicos, privando o cidadão de um direito assegurado pela Constituição Federal Brasileira.

Não obstante, essas difíceis condições de acesso obrigam os profissionais a usarem de outros recursos para chegar à população, como os atendimentos domiciliares, o que se torna uma prática estendida a um grande número de usuários com deficiência. $\mathrm{O}$ atendimento domiciliar, apesar de necessário em muitos casos, consome maior tempo dos profissionais - o que também reduz o número de usuários atendidos por cada profissional e aumenta os custos dos atendimentos.

Os fatores relacionais, que na pesquisa estavam presentes em grande parte dos relatos como um facilitador ao acesso aos serviços, tem papel importante na manutenção das portas abertas dos serviços aos usuários. É a qualidade da relação profissional-da-saúde/usuário/ funcionários, que determina os rumos do processo terapêutico, a qualidade dos vínculos estabelecidos, as possibilidades de construção de projetos terapêuticos e a adesão dos usuários aos mesmos. Mais que pensar e construir o acesso dos usuários aos serviços, há que se pensar o acesso dos profissionais de saúde aos usuários e que afetos, tecnologias, métodos, técnicas, habilidades, saberes estão envolvidos. O comprometimento com o cuidado, com a integralidade, equidade, resolutividade e universalização da assistência contribuiu para o acesso de pessoas aos serviços.

Os resultados da pesquisa sugerem que há muito que se fazer em relação ao acesso das pessoas com deficiência aos serviços de saúde e reabilitação, entendendo que para tanto, se faz necessário uma participação ativa de profissionais, usuários e gestores na sua construção.

SOUZA, C. C. B. X.; ROCHA, E. F. Entry doors or shut doors? Access to rehabilitation within basic health units of the southeastern region of the city of So Paulo - from 2000 to 2006. Rev. Ter. Ocup. Univ. São Paulo, v. 21, n. 3, p. 230-239, set./dez. 2010

\begin{abstract}
Since the Constitution of 1988, equal and universal access to health care is a given right of every Brazilian citizen. However, this law faces numerous barriers to its effectiveness as not all users of the Unified Health System have access to health services; such is the case of people with disabilities and/or impairments. This article presents the results of the research conducted at the Zerbini Foundation - Family Health Program, which aimed to identify the experiences that users with disabilities and their families had when using the rehabilitation services of this program and their thoughts on access to such services. Through semi-structured interviews and use of qualitative methodology, it was possible to take into account different discourses, social positions, and cultural backgrounds. During the research, it became evident, via the interviewees' discourses, that the rehabilitation team had a commitment with the peoples' quality of life. It carried out longitudinal monitoring of families and facilitated access through an active search and home care. However, several barriers to access, especially architectural one, were mentioned by the interviewees. This research helped to detect that, in spite of the strategies used by the rehabilitation team, the issue of access needs to be further discussed and systematically thought through by users, health professionals, services, public policy and governmental agencies; so as to be built up effectively and universally.
\end{abstract}

KEY WORDS: Health services/utilization; Disabled persons/rehabilitation; Family health; Rehabilitation services; Health centers; Primary Health Care.

9. Lei Federal 10098/00, Decreto 3298/99, Decreto 5296/04, instrução Normativa nº 1 de 25/1/2003, NBR9050/04, NBR 14020/97, NBR14021/05, NBR14022/97, NBR 14970 -1, NBR14273/99. 
SOUZA, C. C. B. X.; ROCHA, E. F. Portas de entrada. Rev. Ter. Ocup. Univ. São Paulo, v. 21, n. 3, p. 230-239, set./dez. 2010.

\section{REFERÊNCIAS}

AMIRALIAN, M. L. T.; PINTO, E. B.; GHIRARDI, M. I. G.; LICHTIG, I.; MASINI, E. F. S.; PASQUALIN, L. Conceituando deficiência. Rev. Saúde Pública, v. 34, n. 1, p. 97-103, 2000.

BRASIL. Ministério da Saúde. Coordenação de Atenção a Grupos Especiais, Programa de Atenção à Saúde da Pessoa Portadora de Deficiência (BR). Atenção à pessoa portadora de deficiência no Sistema Único de Saúde: planejamento e organização dos serviços. Brasília: Secretaria de Assistência à Saúde, 1993.

BRASIL. Ministério da Saúde. Política Nacional de Atenção Básica. Brasília: Secretaria de Atenção à Saúde, Departamento de Atenção Básica, 2006. (Série Pactos pela Saúde).

BRASIL. Ministério da Saúde. Portaria GM 154 de 24 de janeiro de 2008 cria os $N A S F S$ - Núcleo de Atenção Integral à Saúde da Família.

CONILL, E.M. Avaliação da integralidade: conferindo sentido para os pactos na programação de metas dos sistemas municipais de saúde. Cad. Saúde Pública, v. 20, n. 5, p. 1417-1423, 2004.

GIOVANELLA, L.; MENDONÇA, M. H. M. Políticas e sistema de saúde no Brasil. In: GIOVANELLA, L.; ESCOREL, S.; LOBATO, L. V. C.; NORONHA, J. C.; CARVALHO, A. L. Políticas e sistema de saúde no Brasil. Rio de Janeiro: Ed. FIOCRUZ, 2008. p.575-625.

HORTALE, V.A.;PEDROZA, M.; ROSA, M.L. G. Operacionalizando as categorias acesso e descentralização na análise de sistemas de saúde. Cad. Saúde Pública, v. 16, n. 1, p.231-239, 2000.

LEVCOVITZ, E.; GARRIDO, N. G. Saúde da família: a procura de um modelo anunciado. Cad. Saúde Família, Ministério da Saúde, v. 1, n. 1, jan/jun. 1996.

MATTOS, R. A. A integralidade na prática (ou sobre a prática da integralidade). Cad. Saúde Pública,v. 20, n. 5, p.1411-1416, 2004.

MERHY, E. E.; FRANCO, T. B. Por uma composição técnica do trabalho em saúde centrada no campo relacional e nas tecnologias leves: Apontando mudanças para os modelos técnoassistenciais. Rev. Saúde em Debate, v. 27, n. 65, p. 316-323, 2003.

PINHEIRO, R.; SILVA, J. P. V.; MACHADO, F. R. Necessidades, demandas e oferta: algumas contribuições sobre os sentidos, significados e valores na construção da integralidade na reforma do setor saúde. Saúde Debate, v. 27, n. 65, p.234-242, 2003.

ROCHA, E. F. Reabilitação de pessoas com deficiência: a intervenção em discussão. São Paulo: Roca, 2006.

ROCHA, E. F.; KRETZER, M. R. Ações de reabilitação de pessoas com deficiência na estratégia da saúde da família da Fundação Zerbini e Secretaria Municipal de Saúde de São Paulo - Região Sudeste Sapopemba/Vila Prudente - período 2000/2006. Rev. Ter. Ocup. Univ. São Paulo, v. 20, n. 1, p. 59-67, 2009.

SOUZA, C. C. B. X. O PSF vivido e o pensado: leitura dos usuários com deficiência e familiares sobre o acesso ao serviço de reabilitação no PSF/QUALIS - Fundação Zerbini. Monografia apresentada ao curso de Terapia ocupacional do Departamento de Fonoaudiologia, Fisioterapia e Terapia Ocupacional da Faculdade de Medicina da USP para obtenção do título de Terapeuta Ocupacional, USP. São Paulo, 2006. 